\title{
A AQUISIÇÃO DE UMA SEGUNDA LÍNGUA E OS ARGUMENTOS ACERCA DA EXISTÊNCIA DE UM PERÍODO CRÍTICO
}

Camila de Bona ${ }^{1}$

\section{RESUMO}

Neste artigo, procuramos demonstrar como os principais pesquisadores da área da aquisição da linguagem têm encarado o assunto da aquisição de uma segunda língua e sua relação com a idade de aquisição, além da possível existência de um período crítico para a aprendizagem de línguas. Para tanto, revisitamos, primeiramente, as noções de competência linguística e gramática universal veiculadas por Noam Chomsky e sua crítica aos pressupostos behavioristas. Abordamos, também, as pesquisas de dois importantes estudiosos da área de aquisição de segunda língua (L2), quais sejam David Birdsong e James Flege, e suas hipóteses acerca dos fatores relevantes e influentes no processo de aprendizado de uma língua adicional. Por fim, abordamos alguns estudos relativos aos mecanismos neurais subjacentes à produção e à compreensão de uma língua adicional, tanto por aprendizes precoces quanto por aprendizes tardios.

Palavras-chave: Aquisição de L2. Período crítico. Aprendizes precoces e tardios.

\section{INTRODUÇÃO}

O período crítico, como conhecido e debatido por diversos pesquisadores, é entendido como aquele período de relativa plasticidade, no qual há a possibilidade de uma mudança relevante no domínio neural. No que tange à Hipótese do Período Crítico para aquisição da linguagem, sabemos que as posições dos estudiosos acerca do assunto podem ir de uma rejeição categórica a uma aceitação fervorosa. A ideia de que a aquisição da linguagem pós-puberdade (depois dos 12 anos) seja menos eficiente ganha adeptos principalmente no que tange ao aprendizado de uma segunda língua. Essa hipótese tem sido tratada não apenas por linguistas, mas 
também por pesquisadores de diversas áreas, tais como a teoria da evolução e a neurofisiologia, os quais buscam entender cada vez mais minuciosamente nosso processamento cognitivo. Alguns estudiosos apontam que a existência de um chamado período crítico não diz respeito somente à área da linguagem propriamente dita, mas também pode ser relacionado a habilidades artísticas, tais como a aptidão para bem-sucedidamente dançar, cantar ou tocar determinado instrumento musical.

Nosso objetivo, neste artigo, é demonstrar como os principais pesquisadores da área da aquisição da linguagem têm encarado o assunto no que concerne, mais especificamente, ao aprendizado de uma segunda língua (doravante L2). Quais são os principais argumentos favoráveis e contrários à hipótese de existência de um Período Crítico? Quais subáreas da gramática (léxico, sintaxe, semântica, fonologia) parecem ser mais afetadas em um aprendizado tardio? Há diferenças de processamento em nossos mecanismos neurais entre línguas aprendidas precoce e tardiamente? Essas são algumas das perguntas que tentaremos responder ao longo desse estudo através de três subseções: primeiramente, vamos revisitar as noções de competência linguística e gramática universal veiculadas por Noam Chomsky e seu argumento relativo à existência de um período crítico; após, revisitaremos as pesquisas de alguns estudiosos acerca da aquisição de uma segunda língua e a relação do período crítico com os aspectos fonológicos, sintáticos e semânticos; finalmente, abordaremos alguns estudos relativos aos mecanismos neurais subjacentes à produção e à compreensão de uma língua adicional, tanto por aprendizes precoces quanto por aprendizes tardios.

\section{A COMPETÊNCIA LINGUÍSTICA E O PERÍODO CRÍTICO}

Como seria possível para uma criança adquirir a habilidade de lidar gramaticalmente com as palavras em um estágio tão precoce de sua vida, com pobreza de estímulos e falta de uma educação formal? Essa foi a questão levantada por Noam Chomsky, o principal responsável pelo desenvolvimento da Gramática Gerativa, em 1965, a qual foi decisiva para definir o conceito de Competência Linguística.

A Competência Linguística é vista por Chomsky como um sistema de conhecimento linguístico que todo e qualquer ser humano possui, a despeito de etnias, classes sociais ou características físicas, e, também, independentemente de 
atributos intelectuais. Esse sistema permite aos falantes partir de um sistema finito de regras (específicas de qualquer língua) à produção de um infinito número de novas sentenças. Além disso, também permite às pessoas distinguir sentenças gramaticais de agramaticais.

Esse conceito vai de encontro à ideia referente à psicologia behaviorista defendida por Burrhus Frederic Skinner, que costumava explicar o comportamento humano através da crença do 'poder dos hábitos', por meio de um processo de condicionamento ao qual os humanos eram submetidos, agindo em uma constante dicotomia de estímulo/resposta (RAPOSO, 1992). Chomsky argumentou que essa teoria não era capaz de explicar o processo de comunicação humana, que é, de fato, muito mais intrigante e desafiador. Se todas as pessoas fazem uso do mesmo sistema biológico para a produção de sons, é permissível pensar que somos geneticamente programados para agir dessa forma, para nos comunicar e sermos entendidos: "Language is not learnt. It grows in the mind. It is, thus, wrong to think that language is taught and misleading to think of it as being learnt" (CHOMSKY, 1976, p.175-176).

Outro argumento contra a teoria behaviorista diz respeito à própria hipótese do Período Crítico para a aquisição da linguagem. Chomsky dá o exemplo de uma criança pequena, filha de imigrantes, que aprende uma segunda língua nas ruas, em contato com outras crianças, de maneira muito mais rápida e fluente que seus pais, mesmo que estes estejam extremamente motivados a e necessitados de aprender a nova língua (CHOMSKY, 1959 apud JUSTI; ARAUJO, 2004).

O aspecto mais notável da Competência Linguística, como o próprio Chomsky enfatizou, é a criatividade da linguagem, a habilidade do falante em produzir novos e diferentes enunciados e ser imediatamente entendido pelo seu ouvinte, constituindo sempre um diálogo inédito composto por sentenças gramaticais toda vez que a comunicação é estabelecida; e, tudo isso, graças ao caráter universal desse sistema inato conhecido como Gramática Universal.

A normal child acquires this knowledge on relatively slight exposure and without specific training. He can then quite effortlessly make use of specific rules and guiding principles to convey his thoughts and feelings to others, arousing in them novel ideas and subtle perceptions and judgments. (...) Language is a mirror of mind in a deep and significant sense. It is a product of human intelligence, created anew in each individual by operations that lie far beyond the reach of will or consciousness. (CHOMSKY, 1971, p.4) 
Enquanto a Competência Linguística diz respeito ao conhecimento da língua de uma forma abstrata, Chomsky define o termo performance para se referir ao seu uso, como um tipo de atualização material da competência linguística (RAPOSO, 1992).

É importante enfatizar que, em se tratando de linguística, a teoria gramatical de Chomsky é, inegavelmente, aquela que mais influência exerceu e a que ainda se sustenta pelo seu dinamismo. Na verdade, o impacto causado pela tese de Chomsky foi notavelmente impressionante, induzindo outros pesquisadores a estudar diferentes aspectos linguísticos, principalmente os concernentes à cognição e aos mecanismos neurais subjacentes à gramática universal.

Birdsong (2006) aponta que o conhecimento linguístico dado pela gramática universal é postulado para lidar com a lacuna existente entre o conhecimento do aprendiz acerca da estrutura linguística e a que input esse aprendiz, de fato, foi exposto. No que concerne à aquisição de uma segunda língua tardiamente, os aprendizes têm acesso a representações linguísticas amplamente desenvolvidas em suas línguas maternas. Com esse conhecimento, complementado pelos procedimentos de aprendizagem de domínio geral, tais como inferências e padronização analógica, além, é claro, do input em L2, a qualidade de parecer um nativo em pelo menos algumas áreas da gramática é inegavelmente possível. Para características ou estruturas linguísticas particulares e abstratas, o acesso à gramática universal é inferido da evidência de que o conhecimento dos aprendizes de L2 não poderia ter sido atingido apenas pelo input de L2 e pela cognição de domínio geral.

\section{AQUISIÇÃO DE UMA SEGUNDA LÍNGUA: QUE FATORES CONSIDERAR?}

\subsection{Birdsong e a centralidade no fator "idade de aquisição"}

Uma das razões pelas quais o estudo da aquisição de uma segunda língua é tão intrigante diz respeito ao fato de que o resultado desta aquisição (diferentemente do resultado de aquisição de L1) é comprovadamente diverso entre os adultos. Os pesquisadores tentam, então, entender qual o efeito que a idade de aquisição exerce nesse resultado. De acordo com Birdsong (2006), a maioria das pesquisas empíricas sobre a questão da idade em L2, realizadas nos últimos 20 anos, tem se 
focado sobre o estado final da $L 2$, tendo em vista que é a evidência desse estado que determina os maiores limites de aquisição.

Há muitas variáveis a serem levadas em conta, as quais podem predizer os resultados de aquisição de uma segunda língua. Entre essas variáveis, podemos citar: idade de primeira exposição à língua (que pode ocorrer em um ambiente formal escolar ou através de visitas ao país dessa L2, além de contato com parentes ou amigos falantes da L2, etc.), duração de residência em um contexto de L2, quantidade de treinamento formal em L2, motivação, integração psicossocial com a cultura da L2, aptidão (que inclui habilidade de imitação, capacidade da memória de trabalho, consciência metalinguística, etc.) e, por fim, estilos e estratégias de aprendizagem (BIRDSONG, 2006).

Birdsong (2006) ressalta que, mesmo com todas essas variáveis em vista, diversos estudos reconhecem que a idade de aquisição é, ainda, a condição mais predizível do estado final da $L 2$, já que se correlaciona negativamente com o estado atingido. Tipicamente, erros de morfossintaxe em produção e/ou erros de julgamentos gramaticais aumentam com o avanço da idade de aquisição, assim como a falta de acurácia e o grau de percepção de um sotaque não nativo. Além disso, em pesquisas entre aprendizes tardios, encontra-se uma maior variação entre os sujeitos no resultado final de aquisição, comparativamente com aprendizes precoces.

Por haver, então, uma forte conexão entre idade de aquisição e proficiência, cabe-nos refletir acerca da conceitualização do chamado 'período crítico'. Em diversos estudos realizados, temos referência a um 'fim do período crítico', qual seja o fim de um período de alta sensibilidade, o fim de uma janela da oportunidade. $\mathrm{O}$ começo desse declínio ocorreria, segundo Singleton (2005 apud BIRDSONG, 2006), em um período que varia desde a tenra idade até o final da adolescência. $O$ interessante é que algumas propostas de período crítico fazem referência a múltiplos períodos críticos, levando em conta diferenças de aquisição em relação à idade no que tange à fonética e à fonologia versus outras áreas de conhecimento e desempenho linguístico.

A noção convencional de período crítico diz respeito não ao período em que os declínios de performance começam, mas sim ao período em que esses declínios se encerram. Uma questão de difícil enquadramento é a de que, empiricamente, os dados comportamentais são geralmente inconsistentes tanto com um período de alta 
sensitividade, cujo fim coincidiria com o final do amadurecimento, quanto com um nivelamento da sensitividade cujo começo coincide com o final da maturação.

Ao caracterizar o estado final da aquisição de L2 como uma falta de sucesso dos adultos em alcançar um nível de proficiência comparável aos observados na aquisição de primeira língua, a visão prevalecente é a de que parecer um nativo é tão raro para esses adultos que já não há relevância para uma teoria de L2. Birdsong (2006) aponta que, recentemente, alguns estudos com imigrantes com um elevado tempo de residência em um país de $\mathrm{L} 2$ e contato com nativos da língua demonstraram que a similitude a um nativo não é comum, mas, também, não é extremamente rara. No que diz respeito à morfossintaxe, muitos falantes tardios da L2 em questão foram avaliados tal como nativos, muito em função do pareamento entre a L1 e a L2; já no que tange à área da pronúncia, os aprendizes que foram considerados como nativos mostraram altos níveis de motivação para parecer um nativo na prática de $\mathrm{L} 2$, além de treinamentos fonéticos em L2. É importante ressaltar que o grau de similitude desses falantes de L2 com nativos é muito menos frequente no nível da pronúncia do que em outros níveis de desempenho linguístico.

Há uma crença geral que atesta que a proficiência por aprendizes tardios de uma segunda língua, se de fato alcançada, será restrita a uma ou a poucas tarefas e que o indivíduo não conseguirá exibir proficiência nativa em uma variada gama de comportamentos linguísticos. No entanto, um recente estudo acerca do estado final de aquisição de inglês como L2 por aprendizes tardios mostrou que a proficiência é, sim, possível (MARINOVA-TODD, 2003 apud BIRDSONG, 2006). Os participantes dessa pesquisa eram aprendizes tardios, com idades de aquisição acima dos 16 anos e com, no mínimo, cinco anos de residência em um país da língua inglesa. As tarefas foram bastante variadas e incluíam questões de pronúncia, acurácia morfossintática, conhecimento lexical em descrições orais, além do uso da língua em narrativas e em discursos. Dos 30 aprendizes tardios, três mostraram acurácia em todos os nove quesitos analisados e outros seis aprendizes se mostraram indistinguíveis de nativos em sete dos nove quesitos. O interessante desse estudo é que ele não apenas englobou tarefas concernentes às áreas centrais da gramática e da pronúncia, mas também envolveu diversidade lexical e competência em discursos e narrativas.

Em outro estudo, loup et al. (1994 apud BIRDSONG, 2006) demonstraram que as diferenças entre aprendizes tardios de $\mathrm{L} 2$ altamente proficientes e nativos 
monolíngues têm sido notadas em áreas de recuperação lexical, resolução de ambiguidade estrutural e detecção de distinções acústicas nas áreas de tonicidade silábica, vozeamento de consoante e duração de vogal. Em relação a questões de pronúncia e de estruturação sintática, temos algumas considerações acerca do desenvolvimento de L1 através do estudo de caso de Genie, a garota que foi privada de qualquer input linguístico a partir de um ano e seis meses até seus 13 anos. A natureza diversa de seu aprendizado linguístico durante os primeiros anos depois de resgatada é notável: Genie mostrou progresso significativo em algumas áreas da gramática e absolutamente nenhum progresso em outras. Seu vocabulário cresceu drasticamente, assim como seus poderes comunicativos; enquanto que, por outro lado, sua entonação permaneceu um tanto excêntrica e Genie nunca foi capaz de produzir uma sentença encaixada ou formular uma pergunta gramaticalmente. Com todos os abusos sofridos por Genie, não seria surpreendente o fato de ela de fato não conseguir aprender inglês em um período tardio; no entanto, não haveria razão para prever que ela seria incapaz de compreender o conceito de dependência de estrutura sintática, enquanto seria bem-sucedida ao depreender facilmente nomes e verbos. Nesse sentido, parece ser plausível atribuir a algumas áreas da gramática a existência de um período crítico (EUBANK; GREGG, 1999).

Outro caso conhecido na literatura linguística diz respeito à Chelsea, a menina que foi diagnosticada erroneamente como emocionalmente perturbada em sua infância, e que foi descoberta como sendo apenas surda quando foi reavaliada, já mulher, em seus 31 anos de idade. Diferente das sentenças de Genie, que aparentavam ter uma mínima complexidade estrutural, os enunciados de Chelsea pareciam não ter estrutura alguma. Gleitman e Newport (1995 apud EUBANK; GREGG, 1999) fizeram algumas especulações notando a diferença de desenvolvimento linguístico entre Chelsea e Genie: o período crítico pode ter uma fase 'marginal' em que parte do desenvolvimento é possível, fase essa que alguns pesquisadores chamaram de período sensitivo. Enquanto que a aquisição de Genie ocorreu em um período marginal, Chelsea perdeu todo o período crítico.

É claro que devemos traçar diferenças entre a aquisição de uma primeira língua tardiamente e a de uma segunda ou terceira língua: no caso de Genie e Chelsea, a arquitetura neural sequer estava desenvolvida. Quando aprendemos uma segunda língua, fica evidente que mudanças são traçadas em nossa arquitetura neural, mas em uma escala muito mais limitada, tendo em vista já haver uma 
organização estabelecida para a primeira língua. No entanto, é notável o fato de que algumas áreas da gramática, principalmente a sintaxe e a fonologia, pareçam estar mais à mercê de um período crítico, tanto na aquisição de L1 quando de L2.

\subsection{Flege e a consideração de outros fatores que podem afetar a pronúncia de uma L2 por adultos e crianças}

Flege (1987) aponta que não há um suporte conclusivo para a existência de um período crítico para o aprendizado de uma língua e que, se esse período de fato existir, há de se procurar por hipóteses testáveis em relação às diferenças de pronúncia de L2, em adultos e crianças. O conceito de período crítico, primeiramente, não foi desenvolvido para descrever o comportamento humano, mas, antes, o animal.

Geralmente, um padrão de comportamento, que pode ser adquirido apenas em um período crítico, exibe características tais como: a aparição em condições de desenvolvimento bem definidas, a impossibilidade de esquecimento ou correção uma vez já estabelecido, o reconhecimento de características da espécie (e não individuais) e a possibilidade de ser aprendido muito antes de ser manifestado. Dessas quatro características mencionadas, apenas a primeira parece se aplicar diretamente ao aprendizado de uma língua humana.

Flege (1987) apresenta inúmeros outros fatores que podem influenciar na pronúncia de uma L2 por adultos e por crianças, tais como fatores de input de L2, fatores de motivação e afetividade e fatores sociais. No que tange aos inputs em L2, temos que é possível controlar a duração de tempo em que crianças e adultos estão imersos em um contexto de fala de L2, mas, mesmo assim, as diferenças de

pronúncia podem derivar de diferenças na qualidade e na quantidade de input recebido. Em um estudo de Cochrane (1977 apud FLEGE, 1987) foi apontada a tendência de crianças japonesas nos Estados Unidos, em falar inglês com um maior número de pessoas, fora de casa, e em um maior número de contextos sociais do que os adultos japoneses.

Em relação aos fatores de motivação, há a ideia de que o grau de autenticidade com o qual um aprendiz pronuncia a $L 2$ pode estar relacionado com o quanto esse falante se sente inclinado (ou obrigado) a pronunciar essa L2 como um nativo da língua. Estudos demonstraram que as crianças são mais propensas a 
imitar o sotaque de um falante se elas se identificam positivamente com ele. Ademais, crianças geralmente apresentam uma maior preocupação com a forma linguística, enquanto que adultos se centram mais na relevância do conteúdo a ser veiculado.

Além disso, temos a constatação de que adultos geralmente têm mais medo de cometer erros e são mais receosos na prática de pronúncia. Um estudo interessante de Guiora (1972 apud FLEGE, 1987) demonstrou que, com a ingestão de álcool minutos antes de imitar um discurso em uma língua estrangeira, os adultos se mostraram muito mais proficientes do que quando sóbrios. Com isso, parece que os adultos são, pelo menos, capazes de pronunciar uma L2 melhor do que eles realmente o fazem, talvez por questões de identidade pessoal, ego linguístico, etc. Então, é possível que as crianças pronunciem melhor uma $L 2$ do que os adultos por apresentarem menos inibições e, também, menos consciência político-social. Em termos sociais, é evidente que a manutenção de um sotaque estrangeiro pode ajudar determinado falante a preservar sua identidade étnica em uma comunidade na qual a L2 é a língua dominante.

Adjungida a esses fatores, temos também a hipótese da competição. Podemos dizer que as crianças tendem a ter uma melhor pronúncia em $L 2$ porque suas representações centrais para as categorias sonoras ainda estão em desenvolvimento, enquanto que nos adultos o processamento padrão de input sonoro já foi modelado por uma experiência linguística prévia em L1.

Para Flege, então, a consideração de outros fatores que não apenas os ligados a hipótese de período crítico e, consequentemente, a idade de aquisição devem ser levados em conta no estudo do aprendizado de uma segunda língua, tanto por adultos quanto por crianças. O aceite inconteste da existência de um período crítico, segundo ele, pode impedir o avanço das pesquisas psicolinguísticas no que diz respeito à descoberta de outros fatores influentes no processo, tais como os mencionados nesta subseção.

\section{IDADE DE AQUISIÇÃO E OS MECANISMOS NEURAIS SUBJACENTES}

Em meio a inúmeros estudos neurolinguísticos realizados recentemente, cabe a nós, nesse momento de exposição, olharmos para os mecanismos neurais 
subjacentes à idade de aquisição. Os pesquisadores da área têm tentado entender como o aprendizado precoce e tardio afetam uma aquisição proficiente.

É interessante atentarmos para o fato de que a idade de aquisição é capaz de afetar outros animais em outros domínios. Nos pássaros, por exemplo, o período de aprendizado geralmente ocorre em três fases: sensória, sensório-motora e cristalizada. Durante a fase sensória, o pássaro escuta a música de um tutor e forma um modelo na memória; a falta de exposição ao som dos adultos nessa fase leva à formação de sons irregulares relativos à sua espécie. Durante a fase sensóriomotora, o pássaro aprende a fazer a conexão entre a música e o modelo; as músicas são treinadas durante essa fase: o feedback auditivo é crucial durante esse período. E, então, na fase cristalizada, os pássaros já estão maduros para produzir as canções específicas de sua espécie e raramente conseguem aprender novas canções. No que diz respeito aos humanos, a idade de aquisição parece afetar, também, os músicos, tanto no nível comportamental quanto no nível neural, refletindo o papel do processamento sensório-motor (HERNANDEZ; LI, 2007)

Pesquisadores demonstraram que, em termos de acesso lexical, a idade de aquisição de determinada palavra afeta significativamente a velocidade e a acurácia com as quais a palavra é acessada e processada. Palavras aprendidas em idade precoce tipicamente extraem tempos menores de resposta que aquelas aprendidas tardiamente, tanto em termos de leitura, decisão lexical visual e auditiva e nomeação de figuras. As palavras aprendidas precocemente são representadas holisticamente, enquanto que as tardias são representadas de forma fragmentada, requerendo reconstrução ou remontagem antes que toda forma fonológica possa ser produzida. Além disso, as palavras aprendidas precocemente serão encontradas mais vezes ao longo de muitos anos de uso do que as aprendidas tardiamente, mesmo que elas tenham baixa frequência (HERNANDEZ; LI, 2007).

No que diz respeito à semântica, palavras aprendidas precocemente apresentam vantagens, já que entram em uma rede representacional antes e afetam as representações semânticas de palavras aprendidas posteriormente, além de apresentarem mais conexões e estabelecerem uma estrutura semântica básica. $E$ isso é comprovado através de um aumento de atividade nos mecanismos neurais:

The increase of activity for late learned compared with early learned items in the fusiform gyrus reflects an increased need for visual form processing (Devlin, Jamison, Gonnerman \& Matthews, 2006; Prive \& Devlin, 2003). 
These results seem consistent with the view that early learned items have more semantic interconnections than do late learned items (HERNANDEZ; LI, 2007, p. 641).

Em todos os estudos revistos por Hernandez e Li (2007), o processamento de itens aprendidos tardiamente envolveu áreas do cérebro responsáveis por um esforço maior de recuperação. A questão do processamento lexical diz respeito tanto a monolíngues quanto a bilíngues, mesmo que estudos tenham comprovado que os efeitos da prática de leitura podem diminuir esse maior esforço na recuperação lexical (ZEVIN; SEIDENBERG, 2002 apud HERNANDEZ; LI, 2007).

Apesar de os efeitos do período crítico em L2 ainda estarem sendo debatidos, os pesquisadores geralmente concordam que a aprendizagem tardia, quando comparada com a precoce, está associada com uma proficiência mais baixa, apesar de alguns indivíduos conseguirem atingir a proficiência de um nativo, como visto nos estudos de Birdsong (1992 apud HERNANDEZ; LI, 2007). Além disso, pesquisas comportamentais sugerem que é a proficiência e não a idade de aquisição que determina as latências de nomeação em tarefas lexicais quando a aquisição de L2 ocorre em um estágio precoce de vida. Tal fato é consistente com a tese de que a idade de aquisição em L2 afeta o processamento da sintaxe, da morfologia e da fonologia mais do que afeta o processamento lexical e semântico (HERNANDEZ; LI, 2007). Essa conjectura é consistente, também, com o caso de Genie no aprendizado de sua primeira língua, no qual ela conseguiu obter sucesso na aquisição de novas palavras, enquanto que sua sintaxe e sua pronúncia não conseguiram atingir um grau maior de desenvolvimento.

Hernandez e Li (2007) demonstraram haver um aspecto importante acerca da proficiência dos falantes, já que falantes altamente proficientes, sejam eles aprendizes precoces ou tardios, mostraram respostas neurais similares tanto para a L1 quanto para a L2. No entanto, as evidências até o momento são inconclusivas no que tange à idade de aquisição e à proficiência na determinação dos padrões neurais e comportamentais no aprendizado de L2.

Segundo os autores, grande número de questões são levantadas a respeito da descoberta de que o processamento sintático é mais sensível que o semântico em relação aos efeitos da idade de aquisição em indivíduos bilíngues. Uma hipótese seria a de que os processos semânticos são mais similares nas duas línguas do indivíduo bilíngue do que os processos sintáticos. Outra hipótese seria a de que 
algum componente do processamento sintático é particularmente afetado pela idade de aquisição. Além disso, muitas sobreposições gramaticais da língua nativa para a L2 podem afetar o processamento sintático da última.

\section{PALAVRAS FINAIS}

Este artigo procurou demonstrar como os principais pesquisadores da área da aquisição da linguagem têm encarado o assunto no que concerne, mais particularmente, ao aprendizado de uma língua adicional. Para tanto, na primeira subseção, revisitamos as noções de competência linguística e gramática universal veiculadas por Noam Chomsky, assim como seu argumento relativo à existência de um período crítico, que ia de encontro aos pressupostos behavioristas, vigentes na década de 1950. Na segunda subseção, revisitamos as pesquisas de dois importantes estudiosos da área de aquisição de L2, quais sejam David Birdsong e James Flege, e suas hipóteses acerca dos fatores relevantes e influentes no processo de aprendizado de uma língua adicional. Por fim, abordamos alguns estudos relativos aos mecanismos neurais subjacentes à produção e à compreensão de uma língua adicional, tanto por aprendizes precoces quanto por aprendizes tardios.

Sabemos que a hipótese de um período crítico ainda é bastante debatida pelos mais renomados pesquisadores e não foi nosso objetivo, nesse pequeno espaço, traçar hipóteses mais contundentes. Nosso propósito maior foi o de esclarecer alguns fatores relevantes na aquisição de uma segunda língua e relatar alguns estudos atuais acerca dos mecanismos neurais subjacentes ao aprendizado precoce e tardio, além do que tudo isso pode implicar em termos gerais.

Em se tratando de pesquisas aplicadas, sabemos que a variada gama de fatores que podem influenciar nos resultados dos estudos é difícil de ser abarcada. O fator idade de aquisição ainda parece ser o fator mais 'concreto' em termos quantitativos, mas há outros subfatores importantes em jogo, tais como quantidade e qualidade de exposição ao input em L2, motivação, objetivos, hábitos intelectuais, etc. Apesar da difícil mensuração de alguns dos fatores investigados, as pesquisas realizadas já nos podem fornecer muitas respostas acerca do nosso desenvolvimento cognitivo, principalmente no que concerne a áreas específicas da 
gramática, tais como a sintaxe e a fonologia, que se mostraram mais suscetíveis a uma idade de aquisição, comparativamente às áreas do léxico e da semântica.

Apesar de termos alguns casos atestados de completa proficiência em idade tardia, percebemos que até mesmo as áreas consideradas menos afetadas através de dados comportamentais, como o léxico e a semântica, apresentam diferenças em dados de pesquisas neurolinguísticas, baseadas na computação dos mecanismos cerebrais, já que foi comprovada a necessidade de um maior esforço por aprendizes tardios no processamento e na recuperação de itens lexicais. Parece que o fator idade de aquisição, mesmo não sendo determinante de fracasso, tem, ainda, um peso considerável no aprendizado de uma língua.

\title{
NOTAS
}

${ }^{1}$ Mestranda do Programa de Pós Graduação em Letras da Universidade Federal do Rio Grande do Sul - UFRGS.

\section{THE ACQUISITION OF A SECOND LANGUAGE AND THE ARGUMENTS ABOUT THE EXISTENCE OF A CRITICAL PERIOD}

\begin{abstract}
In this paper, we try to demonstrate how the most prominent researchers in the area of language acquisition have faced the issue of a second language acquisition and its relation to age of acquisition, besides the possible existence of a critical period for language learning. Therefore, we revisit at first the notions of universal grammar and linguistic competence conveyed by Noam Chomsky and his criticism regarding the behaviorist assumptions. We also address the research of two important scholars in the field of second language acquisition (L2), namely David Birdsong and James Flege, and their assumptions about the most important and influential factors in the process of learning an additional language. Finally, we discuss some studies on the neural mechanisms underlying the production and comprehension of an additional language, both for early learners and late learners.
\end{abstract}

Keywords: L2 acquisition. Critical period. Early and late learners. 


\section{REFERÊNCIAS}

BIRDSONG, David. Age and second language acquisition and processing: a selective overview. Language Learning, v. 56, p. 9-49, 2006.

CHOMSKY, Noam. Selected readings. London, Oxford University Press, 1971.

CHOMSKY, Noam. Reflections on language. Fontana: Collins Press, 1976.

EUBANK, Lynn; GREGG, Kevin R. Critical periods and (second) language acquisition: divide et impera. In: BIRDSONG, David (Ed.). Second language acquisition and the critical period hypothesis. EUA: Lawrence Erlbaum Associates, Publishers, 1999.

FLEGE, James Emil. A critical period for learning how to pronounce foreign languages? Applied Linguistics, v. 8, p.162-177, 1987.

HERNANDEZ, Arturo E.; LI, Ping. Age of acquisition: its neural and computational mechanisms. Psychological Bulletin, n. 133, p. 638-650, 2007.

JUSTI, Francis Ricardo dos Reis; ARAUJO, Saulo de Freitas. Uma avaliação das críticas de Chomsky ao Verbal Behavior à luz das réplicas behavioristas. Psic.: Teor. e Pesq., Brasília, v. 20, n. 3, dez. 2004. Disponível em: $<$ http://www.scielo.br/scielo.php?script=sci_arttext\&pid=S0102-

$37722004000300008 \&$ Ing=en\&nrm=iso >. Acesso em: 3 dez. 2012.

RAPOSO, Eduardo Paiva. Teoria da gramática: a faculdade da linguagem. Lisboa: Caminho, 1992. 